\title{
Geração e distribuição da riqueza das empresas brasileiras do agronegócio à luz da Demonstração do Valor Adicionado (DVA)
}

\section{Cristiane Mallmann Huppes ${ }^{1}$, Denize Demarche Minatti Ferreira $^{2}$, Edgar Maria Ferreira da $\operatorname{Costa}^{3}$ e Hans Michael van Bellen4}

${ }^{1}$ Universidade Federal da Grande Dourados. Faculdade de Administração, Ciências Contábeis e Economia. Rodovia Dourados/Itahum, km 12. Cidade Universitária. Caixa Postal 364. Dourados-MS, Brasil (CEP 79804-970). E-mail: cristianehuppes@ufgd.edu.br.

${ }^{2}$ Universidade Federal de Santa Catarina. Departamento de Contabilidade. Campus Universitário Trindade. Centro Socioeconômico. Florianópolis-SC, Brasil (CEP 88040-970).

${ }^{3}$ Universidade Federal de Santa Catarina. Programa de Pós-Graduação em Contabilidade. Campus Universitário Trindade. Centro Socioeconômico. Florianópolis-SC, Brasil (CEP 88040-970).

${ }^{4}$ Universidade Federal de Santa Catarina. Departamento de Engenharia e Gestão do Conhecimento. Campus Universitário Trindade. Centro Socioeconômico. Florianópolis-SC, Brasil (CEP 88040-970).

Resumo. 0 presente artigo analisa as informações da criação e da geração do Valor Adicionado das empresas do agronegócio que possuem ações negociadas no Brasil, Bolsa, Balcão (B3), no período de 2009 a 2019. Trata-se de um estudo descritivo, documental, que explora por meio da análise vertical a representação de elementos em relação ao seu valor total. Dentre os resultados destaca-se que o consumo de insumos não é equilibrado, mesmo nas empresas de igual segmento. 0 setor têxtil é o que mais gera Valor Adicionado Líquido e, em outros segmentos, algumas empresas possuem Valor Adicionado Recebido em Transferência igual ou superior ao produzido internamente. No que tange a distribuição do Valor Adicionado, a maior fatia é para o item Pessoal (49\%), seguido de Remuneração de Capitais de Terceiros (25\%), representado por juros. Impostos, Taxas e contribuições recebem $20 \%$ da distribuição do Valor Adicionado. A Remuneração do Capital Próprio é a que recebe menor parcela $(6 \%)$ e a Tributação em relação à Receita apresenta inequidade, sendo que a BRF compromete 10,87\% enquanto a JBS, $2,55 \%$. Por fim observa-se que na esfera municipal também ocorre essa discrepância nas empresas Guararapes $(0,98945 \%)$, BRF $(0,10159 \%)$ e JBS $(0,01521 \%)$.

Recebido

$19 / 08 / 2021$

Aceito

$13 / 12 / 2021$

Publicado

$31 / 12 / 2021$

Acesso aberto

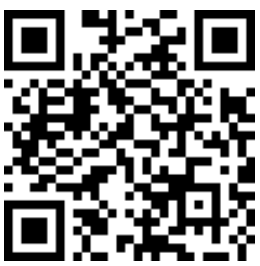

ISSN 2359-1412/RBGAS-2021-0105/2021/8/20/20/1587

Rev. Bras. Gest. Amb. Sustent.

http://revista.ecogestaobrasil.net 
Palavras-chave: Demonstrações contábeis; Agronegócio; CPC; Sustentabilidade.

\begin{abstract}
Generation and distribution of wealth of Brazilian agribusiness companies: An Added Value Statement (AVS) perspective. This paper analyzes the creation and generation of Added Value of public agribusiness companies listed in Brazil, Bolsa, Balcão (B3) from 2009 to 2019. Through vertical analysis, this study explores the representation of elements in relation to their total value. Results show that the consumption of Incomes is not balanced, even in companies of the same segment. The textile sector generates the highest Net Added Value and, in other segments, some companies present an Added Value Received in Transfer equal to or greater than that produced internally. In the distribution of Value Added, most is for the Personnel item (49\%), followed by Compensation for Third-party Capital (25\%) represented by interest. Taxes, rates, and contributions receive $20 \%$ of the Value Added distribution. Equity Remuneration is the one that receives the least part $(6 \%)$ and Taxation in relation to Revenue shows inequity, for example, BRF commits $10.87 \%$ while JBS, 2.55\%. Also, the results show this discrepancy at the municipal level: Guararapes (0.98945\%), BRF (0.10159\%), and JBS (0.01521\%).
\end{abstract}

Keywords: Financial statements; Agribusiness; CPC; Sustainability.

\section{Introdução}

A pandemia da Covid-19 afetou as economias globais no ano de 2020, masnão impediu que o Produto Interno Brasileiro (PIB) do agronegócio brasileiro crescesse 6,75\% (CEPEA, 2020). No ano de 2019, este setor representou 21,4\% do PIB (R\$ 1,55 trilhões), sendo a agricultura responsável por 68\% e a pecuária 32\% (CNA, 2020). Comparado este desempenho com a década de 1970, quando o Brasil importava alimentos para uma população de 90 milhões de habitantes, o crescimento é notável, em que passados 50 anos, o agronegócio brasileiro alimenta 1,5 bilhões de pessoas (BRASILABRO, 2020). Esta produção, se considerado o nível tecnológico existente nos anos 70, corresponderia a 130 milhões de hectares, cerca de $15 \%$ do território brasileiro, que por meio do uso de tecnologias, ocupa uma área de 7,8\% (EMBRAPA, 2020).

Estes aspectos corroboram com significativa importância do setor do agronegócio para a economia brasileira, movimentando recursos financeiros e empregando pessoas ao longo da cadeia produtiva. 0 agronegócio brasileiro também chama atenção por aspectos negativos que envolvem questões ambientais. Em carta pública, o Conselho Indígena Missionário (CIMI, 2020) descreve uma "história que a História não conta", cujo o título é "O agro é fogo", atribuindo aos grileiros e desmatadores os incêndios ocorridos no Pantanal, no Cerrado e na Amazônia. Camargos e Campos (2020) associam queimadas ao agronegócio, acusando pecuaristas do Mato Grosso como responsáveis pelo início do fogo no Pantanal Mato-Grossense, citando os grupos Amaggi e Bom Futuro, fornecedores das multinacionais JBS, Marfrig e Minerva.

Perspectivas positivas e negativas envolvem a agropecuária no Brasil e, não há como citar o agronegócio, sem referenciar a sua dependência aos fatores de produção, 
terra, trabalho, capital e tecnologia. Os elementos trabalho, capital e tecnologia são evidenciados pelo crescimento econômico, mas o elemento terra, além de uma ocupação geográfica, envolve a biodiversidade e recursos naturais. Entram em cena conceitos e discussões sobre sustentabilidade, cuja definição é apresentada no Relatório de Brundtland (1987) define o desenvolvimento sustentável, como aquele que "satisfaz as necessidades presentes, sem comprometer a capacidade das gerações futuras de suprir suas próprias necessidades". Zanella e Lago (2017) verificaram uma crescente na produção científica sobre o tema, onde os focos versaram sobre elaboração de indicadores e índices de sustentabilidade.

A contabilidade como sistema de informação, traz ao público dados sobre a situação econômico-financeira de uma determinada empresa ou conglomerado destas, possibilitando informações para seus usuários internos ou externos. Para além de informações econômicas e financeiras, a contabilidade corrobora com informações relativas à responsabilidade social empresarial, pauta das discussões sobre sustentabilidade, nominado de Balanço Social, que incorpora dados ambientais e sociais, segmentado em: Balanço Ambiental; Balanço de Recursos Humanos; Demonstração do Valor Adicionado; e, Benefícios e Contribuições à sociedade em geral (Perez Junior e Begalli, 2015; Tinoco e Kraemer, 2011).

A Demonstração do Valor Adicionado (DVA) faz parte do conjunto das Demonstrações Financeiras Padronizadas (DFP) e ultrapassa a visão de patrimônio e resultado, demonstrando geração e distribuição da riqueza criada e movimentada pela empresa. Recursos econômicos, sociais e ambientais permeiam as discussões sobre a continuidade das empresas e, sendo o agronegócio dependente de recursos ambientais, torna-se um case empresarial importante. Callado et al. (2017) evidenciaram a necessidade de pesquisas na área de contabilidade e sustentabilidade com base em mecanismos e informações contábeis e, é neste universo que o presente estudo pretende corroborar.

Em destaque, as empresas do agronegócio brasileiro que integram a lista das 400 Maiores do Agronegócio, publicada pela Revista Exame no ano de 2019 e possuem ações negociadas na B3 são foco deste estudo. A questão de pesquisa rastreia: Quais os elementos que compõem a criação e como é distribuída a riqueza destas empresas? Quanto ao período, tendo em vista a alteração da base de dados do acesso às informações promovido pela B3 a partir do ano de 2009, este se limita ao período de 2009 até 2019. Assim, o objetivo geral é descrever e analisar os elementos que compõem a criação e como é distribuída a riqueza das empresas do agronegócio brasileiro.

A base teórica é construída com base em estudos que apontam o constructo dos pensamentos que deram origem à DVA, questões técnicas de elaboração da demonstração e descrição de pesquisas que antecedem. Em seguida estão delineados os procedimentos metodológicos, relatando a composição da amostra e a metodologia aplicada. Por fim, é descrita a apresentação e análise dos resultados, seguida das conclusões, com ênfase aos achados e possíveis novas discussões.

\section{Demonstração do Valor Adicionado (DVA)}

Anterior à exigência legal, estudos apontavam para a relevância da DVA, argumentando a capacidade de relato sobre como uma empresa cria valor e, enquanto item do balanço social, principal forma de medição e demonstração de geração e distribuição da riqueza (Luca, 1998; Santos, 2007; Iudícibus et al., 2010). Machado et al. (2015) demonstraram que as informações da DVA refletem no preço das ações, ou seja, o conteúdo desta informação contábil para o mercado de capitais evidencia-se como relevante na explicação da variação na precificação delas.

A DVA aponta números diferentes quando comparada as demais informações das outras Demonstrações Contábeis, com dados direcionados ao lucro e forma de apuração, 
pressupondo informações financeiras para gestores e investidores. Comumente comparada à Demonstração do Resultado do Exercício (DRE), cujas informações estão focadas no lucro contábil, na DVA as informações são abrangentes e se referem a distribuição da riqueza gerada e distribuída pela entidade. Esta nova perspectiva informacional diz respeito à responsabilidade social da empresa, demonstrando a remuneração dos fatores de produção, que corroboram à formação da riqueza da organização (Cunha et al., 2005; Santos, 2007).

A definição da DVA fundamenta-se em conceitos macroeconômicos, em que a parcela gerada pela empresa para a formação do Produto Interno Bruto (PIB) é apresentada, expondo o quanto a entidade agrega valor aos insumos adquiridos de terceiros, vendidos ou consumidos em determinado período (CPC, 2008). Esta demonstração evidencia a riqueza econômica gerada pela empresa, resultado do esforço coletivo dos agentes envolvidos, tais como financiadores, governo, fornecedores, clientes e empregados (Luca, 1998; CPC, 2008; Iudícibus et al., 2010).

Os modelos de apresentação da DVA são três, cada um direcionado a um tipo de organização econômica: empresas em geral (utilizado pelas entidades mercantis (comerciais e industriais) e prestadoras de serviços), instituições financeiras bancárias (atividades de intermediação financeira) e, seguradoras (modelo sugerido pela Superintendência de Seguros Privados - SUSEP). As nomenclaturas e descrições técnicas apresentadas no CPC, específicas para empresas em geral, caracterizam as empresas analisadas neste estudo (Tabela 1 ).

Tabela 1. Síntese dos elementos que compõem a Formação e da Distribuição da Riqueza.

\begin{tabular}{|c|c|c|}
\hline \multirow{6}{*}{ 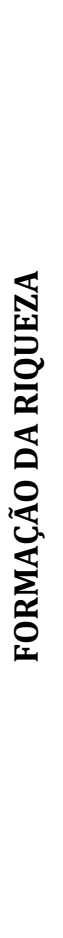 } & Valor Adicionado & $\begin{array}{l}\text { Riqueza criada pela empresa, incluindo o valor adicionado } \\
\text { recebido em transferência (produzido por terceiros) }\end{array}$ \\
\hline & $\begin{array}{l}\text { Receita de venda } \\
\text { mercadorias, produtos e } \\
\text { serviços }\end{array}$ & $\begin{array}{l}\text { Valores reconhecidos na contabilidade, pelo regime de } \\
\text { competência, incluídos na demonstração do resultado do } \\
\text { período. }\end{array}$ \\
\hline & Outras receitas & $\begin{array}{l}\text { Alienação de ativos não-circulantes, venda de imobilizado, } \\
\text { investimentos e outras transações incluídas na DRE que não } \\
\text { configurem reconhecimento de transferência de riqueza criada } \\
\text { por outras entidades. } \\
\text { Valores que não transitam na DRE: construção de ativos de uso } \\
\text { próprio; juros pagos ou creditados incorporados à ativos de longo } \\
\text { prazo. } \\
\text { Estoques de longa maturação e juros incorporados serão } \\
\text { destacados no momento de baixa. }\end{array}$ \\
\hline & $\begin{array}{l}\text { Insumos adquiridos de } \\
\text { terceiros }\end{array}$ & $\begin{array}{l}\text { Aquisições de matérias primas, mercadorias, materiais, } \\
\text { energia, serviços que tenham sido transformados (estoques } \\
\text { não compõem a formação da riqueza criada e distribuída) }\end{array}$ \\
\hline & $\begin{array}{l}\text { Depreciação, } \\
\text { amortização e exaustão }\end{array}$ & $\begin{array}{l}\text { Valores reconhecidos, utilizados para conciliação de fluxo de } \\
\text { caixa das atividades operacionais e o resultado líquido do } \\
\text { exercício. }\end{array}$ \\
\hline & $\begin{array}{l}\text { Valor Adicionado } \\
\text { recebido em } \\
\text { transferência }\end{array}$ & $\begin{array}{l}\text { Riqueza não criada pela entidade, e sim por terceiros(receitas } \\
\text { financeiras, de equivalência patrimonial, dividendos, aluguel, } \\
\text { royalties). Para evitar dupla contagem, precisa ficar destacado. }\end{array}$ \\
\hline
\end{tabular}


Tabela 1. Continuação.

\begin{tabular}{|c|c|c|}
\hline \multirow{4}{*}{ 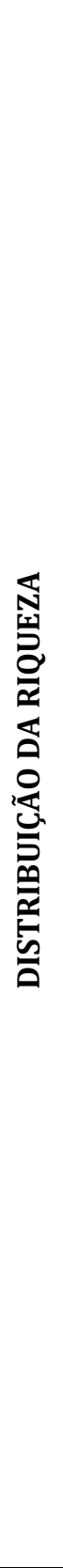 } & Pessoal & $\begin{array}{l}\text { Valores de custo apropriados resultado do exercício. } \\
\text { Remuneração direta: salários, } 13^{0} \text { salário, honorários } \\
\text { (inclusive pagamentos baseados em ações), férias, comissões, } \\
\text { horas extras, participação de empregados nos resultados. } \\
\text { Benefícios: assistência médica, alimentação, transporte, planos } \\
\text { de aposentadoria etc. } \\
\text { FGTS: depósitos em conta vinculada dos empregados. }\end{array}$ \\
\hline & $\begin{array}{l}\text { Impostos, taxas e } \\
\text { contribuições }\end{array}$ & $\begin{array}{l}\text { Federais: tributos devidos à União, inclusive os repassados no } \\
\text { todo ou em parte aos Estados, Municípios, Autarquias etc. } \\
\text { (IRPJ, CSSL, IPI, CIDE, PIS, COFINS e contribuição sindical } \\
\text { patronal). } \\
\text { Estaduais: tributos devidos aos Estados, inclusive os } \\
\text { repassados no todo ou em parte aos Municípios, Autarquias } \\
\text { etc. (ICMS e IPVA). } \\
\text { Municipais: tributos devidos aos Municípios, inclusive os que } \\
\text { são repassados no todo ou em parte às Autarquias (ISS e } \\
\text { IPTU). } \\
\text { Para impostos compensáveis (ICMS, IPI, PIS e COFINS) } \\
\text { considerar os valores devidos ou já recolhidos e valores } \\
\text { incidentes sobre os itens considerados como "insumos } \\
\text { adquiridos de terceiros". }\end{array}$ \\
\hline & $\begin{array}{l}\text { Remuneração de } \\
\text { capitais de terceiros }\end{array}$ & $\begin{array}{l}\text { Valores pagos ou creditados aos financiadores externos de } \\
\text { capital. } \\
\text { Juros: despesas financeiras, variações cambiais passivas. } \\
\text { Aluguéis: aluguéis, despesas com arrendamento operacional, } \\
\text { pagos ou creditados a terceiros, inclusive os acrescidos aos } \\
\text { ativos. } \\
\text { Outras: remunerações que configurem transferência de } \\
\text { riqueza a terceiros (royalties, franquia, direitos autorais etc. }\end{array}$ \\
\hline & $\begin{array}{l}\text { Remuneração de } \\
\text { capitais próprios }\end{array}$ & $\begin{array}{l}\text { Relativos à remuneração atribuída aos sócios e acionistas. } \\
\text { Juros sobre o Capital Próprio (JCP) e dividendos (do próprio } \\
\text { exercício). Desconsiderar dividendos com base em lucros } \\
\text { acumulados de exercícios anteriores. } \\
\text { Lucros retidos e prejuízos do exercício: lucro do exercício } \\
\text { destinados às reservas, inclusive JCP quando tiverem esse } \\
\text { tratamento. Os casos de prejuízo, incluído com sinal negativo. } \\
\text { As quantias destinadas aos sócios e acionistas na forma de JCP, } \\
\text { independentemente de serem registradas como passivo (JCP a } \\
\text { pagar) ou como reserva de lucros, devem ter o mesmo } \\
\text { tratamento dado aos dividendos (somente do próprio } \\
\text { exercício) }\end{array}$ \\
\hline
\end{tabular}

Fonte: Adaptado do CPC (2008).

A DVA é um demonstrativo que evidencia a riqueza gerada pela empresa em determinado período, bem como sua distribuição que é medida a partir da diferença entre o valor da produção e os bens e serviços gerados pela entidade. Quanto a estrutura, a DVA apresenta duas partes: (I) formação da riqueza: conjunto da receita menos insumos adquiridos de terceiros, retenções (depreciação, amortização e exaustão) e (II) distribuição dessa riqueza, composta por pessoal, impostos, taxas, juros, aluguéis, juros sobre capital próprio e dividendos, lucros/prejuízos do exercício (CPC, 2008).

Trabalhos anteriores que evidenciaram, em conjunto, os três temas, (I) Demonstração do Valor Adicionado, (II) Agronegócio e (III) Sustentabilidade, não são frequentes, o que ressalta a importância de expandir o uso da DVA e a evidenciação de 
suas informações por entidades ligadas ao setor agrícola. Neste sentido, estudos que debatem a DVA, mesmo que em outros setores, estão apresentados na Tabela 2, com vistas a auxiliar as discussões do presente estudo.

Tabela 2. Estudos relacionados.

\begin{tabular}{|c|c|c|}
\hline Autores/Ano & Objetivo & Resultado \\
\hline $\begin{array}{l}\text { Tinoco et al. } \\
\text { (2011) }\end{array}$ & $\begin{array}{l}\text { Descrever, identificar, mensurar e } \\
\text { comparar através da DVA, a carga } \\
\text { tributária de empresas brasileiras. }\end{array}$ & $\begin{array}{l}\text { De } 2005 \text { a 2007, os tributos médios } \\
\text { verificados foram superiores àqueles } \\
\text { divulgados pelo IBGE;sendo o governo o } \\
\text { maior beneficiário na amostra. }\end{array}$ \\
\hline $\begin{array}{c}\text { Almeida e } \\
\text { Silva (2014) }\end{array}$ & $\begin{array}{l}\text { Verificar a qualidade das DVAs } \\
\text { (comparabilidade) de empresas de } \\
\text { capital aberto industriais, } \\
\text { comerciais e prestadoras de } \\
\text { serviços, no exercício de 2011. }\end{array}$ & $\begin{array}{l}\text { Há inconsistências que comprometem a } \\
\text { comparabilidade no que tange: nível de } \\
\text { detalhamento, falta de Notas Explicativas; e, } \\
\text { inadequação de formato (totais e subtotais). }\end{array}$ \\
\hline $\begin{array}{l}\text { Degenhard, } \\
\text { Vogt e Hein } \\
\quad(2014)\end{array}$ & $\begin{array}{l}\text { Analisar a relação do PIB dos } \\
\text { municípios do Estado de Santa } \\
\text { Catarina com dados das DVA do } \\
\text { Agronegócio, Indústria, Serviços e } \\
\text { Administração }\end{array}$ & $\begin{array}{l}\text { Há forte relação do PIB com as DVAs; a DVA } \\
\text { da Administração quando analisada no } \\
\text { conjunto apresentou menor correlação com } \\
\text { o PIB e na análise individual, a DVA do } \\
\text { Agronegócio apresentou menor relação com } \\
\text { o PIB. }\end{array}$ \\
\hline $\begin{array}{c}\text { Cardoso et al. } \\
\text { (2015) }\end{array}$ & $\begin{array}{l}\text { Analisar a distribuição de riqueza } \\
\text { aos agentes econômicos de } \\
\text { diferentes setores, no exercício de } \\
\text { 2013, sobretudo em relação ao } \\
\text { governo. }\end{array}$ & $\begin{array}{l}\text { Maior destinação àImpostos, Taxas e } \\
\text { Contribuições; Telecomunicações, Energia e } \\
\text { a Indústria Digital com maior distribuição e } \\
\text { o setor Farmacêutico e Indústria da } \\
\text { Construçãomostrando menor distribuição. }\end{array}$ \\
\hline $\begin{array}{l}\text { Melo et al. } \\
\text { (2017) }\end{array}$ & $\begin{array}{l}\text { Verificar a distribuição da riqueza } \\
\text { gerada, por meio da DVA,das } \\
\text { empresas de capital aberto nas } \\
\text { cinco regiões do Brasil nos anos de } \\
2013 \text { e } 2014 \text {. }\end{array}$ & $\begin{array}{l}\text { Em 2013, os setores dePessoal, Impostos, } \\
\text { Taxas e Contribuições, e Remuneração de } \\
\text { Capitais de Terceiros, na região Centro- } \\
\text { Oeste e Remuneração do Capital Própriono } \\
\text { Sul foram as que mais distribuíram e em } \\
\text { 2014, Pessoal e Remuneração de Capitais de } \\
\text { Terceiros noCentro-Oeste, Impostos, Taxas } \\
\text { e Contribuições no Sudeste e, Remuneração } \\
\text { com Capital Próprio na região Sul. }\end{array}$ \\
\hline $\begin{array}{l}\text { Londero, } \\
\text { Stanzani e } \\
\text { Santos } \\
(2019)\end{array}$ & $\begin{array}{l}\text { Avaliar a criação e distribuição de } \\
\text { riqueza pelas } \\
\text { agropecuárias }\end{array} \begin{array}{lr}\text { brasileiras } \\
\text { comparando o processo com } \\
\text { empresas de finalidade lucrativa. }\end{array}$ & $\begin{array}{l}\text { A distribuição para pessoal, governo e } \\
\text { remuneração de capital de terceiros é } \\
\text { semelhante, diferenciando-se na } \\
\text { remuneração de capital próprio. }\end{array}$ \\
\hline $\begin{array}{l}\text { Silva et al. } \\
(2020)\end{array}$ & $\begin{array}{l}\text { Apresentar a geração e a } \\
\text { distribuição do valor adicionado das } \\
\text { organizações de seguros listadas na } \\
\text { B3 no período de } 2015 \text { a } 2017 \text {. }\end{array}$ & $\begin{array}{l}\text { A maior distribuição foi para Reservas de } \\
\text { Lucros, ou seja, Remuneração de Capital } \\
\text { Próprio, sendo que Governo e Funcionários } \\
\text { foram os que menos se beneficiaram. }\end{array}$ \\
\hline $\begin{array}{l}\text { Silva, Oliveira } \\
\text { e Gonzales } \\
\text { (2021) }\end{array}$ & $\begin{array}{l}\text { Analisar a distribuição da riqueza } \\
\text { gerada pelas entidades do } \\
\text { agronegócio dos diversos setores da } \\
\text { economia brasileira no biênio } 2017 \\
\text { e 2018. }\end{array}$ & $\begin{array}{l}43,95 \% \text { da riqueza gerada é distribuída } \\
\text { para Pessoal e Algodão e Grãos destinou } \\
33,79 \% \text { a título de Impostos e o setor de } \\
\text { Madeira e Celulose remunerou Capital de } \\
\text { Terceiros em } 54,93 \% \text {. }\end{array}$ \\
\hline $\begin{array}{l}\text { Costa e } \\
\text { Valentim } \\
(2021)\end{array}$ & $\begin{array}{l}\text { Demonstrar a distribuição do valor } \\
\text { adicionado dos bancos listados na } \\
\text { B3 que compõe o Índice Financeiro } \\
\text { (IFNC) nos anos de } 2018 \text { a } 2019 \text {. }\end{array}$ & $\begin{array}{l}\text { O Valor Adicionado aos elementos relatados } \\
\text { foi em média foram Remuneração de Capital } \\
\text { Próprio (47\%), Pessoal } \quad(34 \%) \text {, Governo } \\
(9 \%) \text { e Remuneração de Capital de } \\
\text { Terceiros (3\%). }\end{array}$ \\
\hline
\end{tabular}


Os estudos, por mais que tratem de outros assuntos, corroboram com as discussões desta pesquisa, tais como os aspectos sobre a carga tributária trazem indagações sobre mudanças ocorridas desde os períodos analisados. Ainda, relacionam a distribuição do Valor Adicionado ao PIB que contribuem em observações acerca da localização geográfica das empresas deste estudo e, por fim a comparação de empresas agropecuárias com e sem fins lucrativos possibilitam uma comparação de distribuição do Valor Adicionado frente a outros segmentos da economia.

\section{Procedimentos metodológicos}

O primeiro aspecto do estudo é a análise documental para obtenção dos dados da DVA, elaborada para mostrar a riqueza gerada e a distribuição (Flick, 2009). A análise documental favorece a observação do processo de maturação ou de evolução do objeto de estudo (Cellard, 2008). Esse trabalho explora e descreve o conteúdo das DVAs por meio da análise vertical da DVA, que possibilita a visão dos elementos que compõem a geração e a distribuição da riqueza assim como a comparação entre as empresas(Matarazzo, 2010; Diniz, 2015; Marion, 2019).

Tabela 3. Empresas do Agronegócio brasileiro que integram o estudo.

\begin{tabular}{|c|c|c|c|c|c|c|}
\hline № & $\begin{array}{c}\text { Classificação } \\
400 \text { Agro } \\
\text { Exame }\end{array}$ & Empresa & Cidade & $\mathbf{U F}$ & Segmento & $\begin{array}{c}\text { Início } \\
\text { Açõe } \\
\text { s } \\
\text { Bolsa }\end{array}$ \\
\hline 1 & 66 & Biosev & São Paulo & $\mathrm{SP}$ & Açúcar e álcool & 2012 \\
\hline 2 & 68 & São Martinho & Pradópolis & SP & Açúcar e álcool & 2006 \\
\hline 3 & 45 & Heringer & Viana & ES & Adubos e defensivos & 2006 \\
\hline 4 & 55 & Camil & São Paulo & $\mathrm{SP}$ & Algodão e grãos & 2017 \\
\hline 5 & 165 & Josapar & Porto Alegre & RS & Algodão e grãos & 1997 \\
\hline 6 & 91 & SLC Agrícola & Porto Alegre & RS & Algodão e grãos & 2006 \\
\hline 7 & 215 & Terra Santa & São Paulo & SP & Algodão e grãos & 2005 \\
\hline 8 & 5 & BRF & Itajaí & $\mathrm{SC}$ & Aves e suínos & 1997 \\
\hline 9 & 4 & JSB & São Paulo & $\mathrm{SP}$ & Carne bovina & 2006 \\
\hline 10 & 17 & Marfrig & São Paulo & SP & Carne bovina & 2006 \\
\hline 11 & 24 & Minerva Foods & Barretos & $\mathrm{SP}$ & Carne bovina & 2006 \\
\hline 12 & 187 & Irani & Porto Alegre & RS & Madeira e celulose & 1997 \\
\hline 13 & 15 & Klabin & São Paulo & $\mathrm{SP}$ & Madeira e celulose & 1997 \\
\hline 14 & 12 & Suzano/Fibria & São Paulo & $\mathrm{SP}$ & Madeira e celulose & \\
\hline 15 & 10 & $\begin{array}{c}\text { Suzano Papel e } \\
\text { Celulose }\end{array}$ & Salvador & $\mathrm{BA}$ & Madeira e celulose & 1997 \\
\hline 16 & 374 & Metisa & Timbó & $\mathrm{SC}$ & $\begin{array}{c}\text { Máquinas, equipamentos e } \\
\text { ferramentas }\end{array}$ & 1997 \\
\hline 17 & 30 & M. Dias Branco & Eusébio & $\mathrm{CE}$ & $\begin{array}{c}\text { Óleos, farinhas e } \\
\text { conservas }\end{array}$ & 2005 \\
\hline 18 & 323 & Cedro e Cachoeira & $\begin{array}{c}\text { Belo } \\
\text { Horizonte }\end{array}$ & MG & Têxtil & 1998 \\
\hline 19 & 294 & Döhler & Joinvile & $\mathrm{SC}$ & Têxtil & 1997 \\
\hline 20 & 164 & Guararapes & Natal & $\mathrm{RN}$ & Têxtil & 1997 \\
\hline 21 & 358 & Karsten & Blumenau & $\mathrm{SC}$ & Têxtil & 1997 \\
\hline 22 & 306 & Santanense & $\begin{array}{l}\text { Montes } \\
\text { Claros }\end{array}$ & MG & Têxtil & 1997 \\
\hline
\end{tabular}

Fonte: 400 Maiores Agronegócio 2019 (2020) e B3 (2020). 
Para detectar discrepâncias e individualidades nos valores monetários apresentados pelas companhias, é apresentada uma descrição da composição dos insumos e das retenções em relação à receita, a formação e a distribuição do valor adicionado e por fim, uma análise de valores absolutos e relativos a partir do cálculo da média, máxima e mínima, obtidos pelo somatório dos valores corrigidos nas DVAs ao longo do período da análise.

\section{Definição da amostra}

A partir do Ranking da Revista Exame "400 maiores agronegócios", edição de 2019, foram coletados os dados da DVA das empresas que possuem ações negociadas na B3com um total de 22 empresas que compõem a população, nominadas em ordem de segmento (Tabela 3).

A Camil passou a divulgar a partir de 2015 e a Suzano/Fibria não possui demonstrações isoladas devido à fusão com a Suzano, sendo excluídas do estudo. A geração e distribuição da riqueza das 20 empresas ao longo de 10 anos (2009 a 2019) foram analisadas e seus valores corrigidos até outubro de 2019 com as taxas obtidas no website do Instituto Brasileiro de Geografia e Estatística (IBGE, 2020).

Biosev e São Martinho, ambas do segmento Açúcar e Álcool, foram corrigidas de acordo com as taxas do respectivo ciclo operacional e houve ainda alteração da unidade monetária da Metisa, uma vez que os valores de suas demonstrações (2013, 2012, 2011 e 2010) estavam em "Unidades de Reais" enquanto as demais empresas em "Milhares de Reais". Ainda, foi verificado que a unidade monetária da DVA da Biosev em 2012 disponibilizada pela B3, informa "Unidade de Reais", sendo correto "Milhares de Reais" segundo os relatórios financeiros da Biosev.

Tabela 4. Taxas de atualização monetária.

\begin{tabular}{|c|c|c|c|c|c|c|c|}
\hline \multicolumn{3}{|c|}{ Ciclo Operacional 1o Jan a 31 Dez } & \multicolumn{3}{c|}{ Ciclo Operacional 1o Abr a 31 Mar } \\
\hline $\begin{array}{c}\text { Data Publ } \\
\text { DVA }\end{array}$ & Taxa & $\begin{array}{c}\text { Data Publ } \\
\text { DVA }\end{array}$ & Taxa & $\begin{array}{c}\text { Data Publ } \\
\text { DVA }\end{array}$ & Taxa & $\begin{array}{c}\text { Data Publ } \\
\text { DVA }\end{array}$ & Taxa \\
\hline $31 / 12 / 2010$ & 1,7123 & $31 / 12 / 2015$ & 1,2219 & $31 / 03 / 2011$ & 1,6742 & $31 / 03 / 2016$ & 1,1845 \\
\hline $31 / 12 / 2011$ & 1,6057 & $31 / 12 / 2016$ & 1,1421 & $31 / 03 / 2012$ & 1,5817 & $31 / 03 / 2017$ & 1,1307 \\
\hline $31 / 12 / 2012$ & 1,5215 & $31 / 12 / 2017$ & 1,1110 & $31 / 03 / 2013$ & 1,4878 & $31 / 03 / 2018$ & 1,0994 \\
\hline $31 / 12 / 2013$ & 1,4384 & $31 / 12 / 2018$ & 1,0678 & $31 / 03 / 2014$ & 1,4078 & $31 / 03 / 2019$ & 1,0582 \\
\hline $31 / 12 / 2014$ & 1,3499 & $31 / 12 / 2019$ & 1,0339 & $31 / 03 / 2015$ & 1,3071 & $31 / 03 / 2020$ & 1,0175 \\
\hline
\end{tabular}

Fonte: IBGE (2020).

As taxas correspondem ao Índice de Preços ao Consumidor Amplo (IPCA) considerado oficial pelo governo federal (IBGE, 2020). Na sequência foram definidasas informações a serem analisadas por meio da análise vertical da DVA, em seus elementos: Receitas; Insumos Adquiridos de Terceiros; Retenções; Valor Adicionado Líquido Produzido; Valor Adicionado Recebido em Transferência; Distribuição do Valor Adicionado; Pessoal; Impostos, Taxas e Contribuições; Remuneração de Capitais de Terceiros e Remuneração de Capitas Próprios.

\section{Resultados}

\section{Receita, Insumos e Retenções}

Os valores de Insumos e Retenções são díspares, pois são de segmentos diferentes, porém, se esperavaque as empresas do mesmo segmento apresentassem comportamento próximo, principalmente no que se refere aos Insumos (Figura 1). 


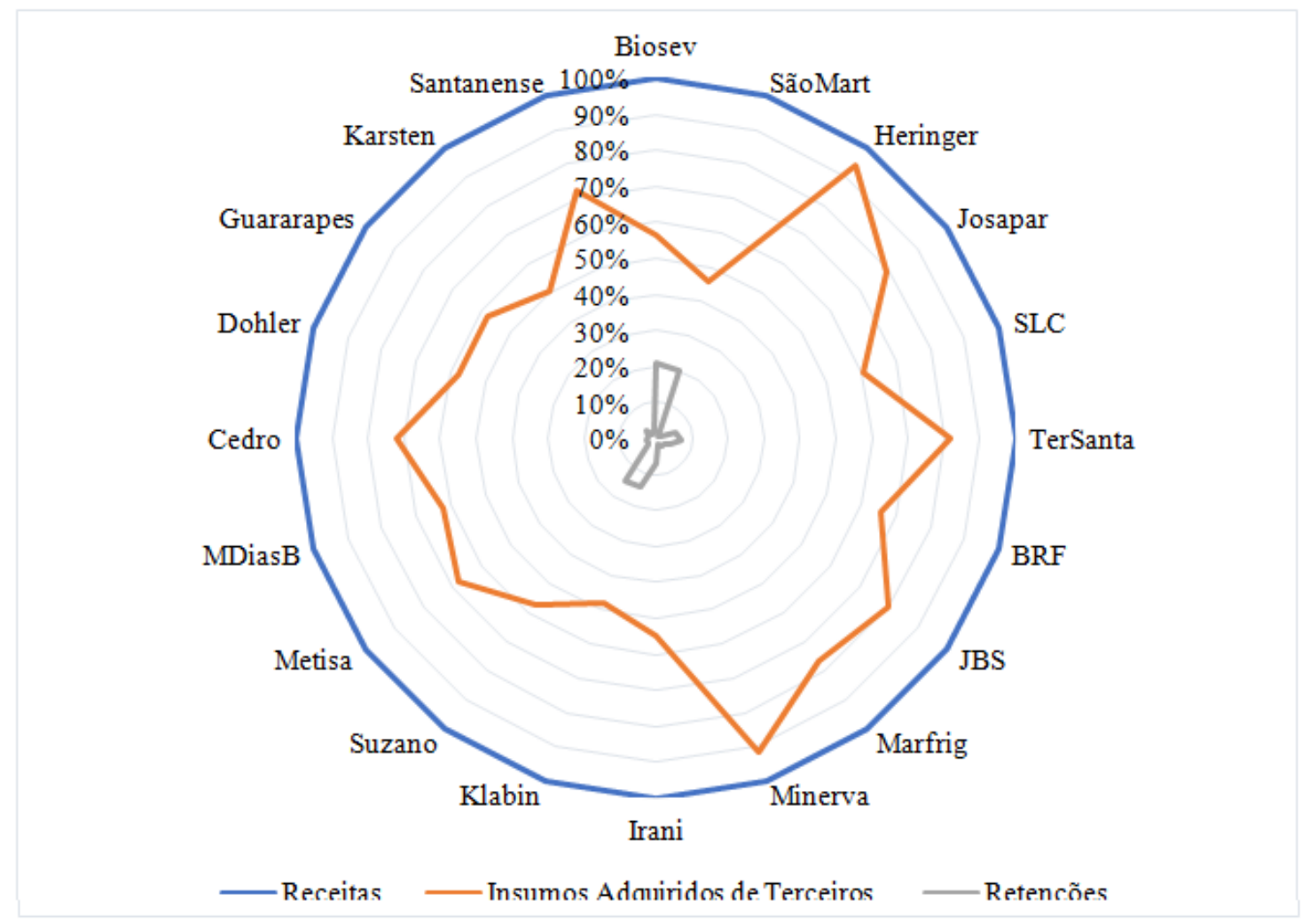

Figura 1. Receita, insumos e retenções das empresas de capital aberto do agronegócio brasileiro.

Biosev e SãoMart do segmento Açúcar e álcool não mostram o mesmo comportamento nos Insumos, sendo próximas nas retenções, a Biosev apresenta um mínimo/máximo de insumos em relação a receita que oscila entre 34\% (2012) e 73\% (2015). Ao observar a composição dos valores dos insumos, destacam-se os anos de 2013, 2014 e 2016, 2017, onde aumentam os custos de produção em mais de 50\%, diminuídos pela dedução de Recuperação de Valores de Ativos e, quanto a SãoMart, os números são mais constantes, oscilando entre 42\% (2020) e 50\% (2014).

$\mathrm{Na}$ análise do segmento de Algodão e grãos (Josapar, SLC e TerSanta), Josapar e TerSanta apresentam o valor de Insumos em todos os anos, superior a $73 \%$, enquanto a SLC opera com custo máximo de 65\%. Os valores corrigidos dos Insumos nas empresas Josapar e SLC permanecem aproximados, diferente da TerSanta que oscila de 50\% para mais e para menos, no decorrer dos anos.

Das empresas analisadas, quatro pertencem a produção de proteína animal, BRF Aves e suínos e, JBS, Marfrig e Minerva - Carne bovina. Na análise, destas quatro empresas, o valor dos insumos não apresenta flutuações; para Aves e Suínos o mínimo é de 61\% (2015) e máximo de 68\% (2018). Destaca-se que para as empresas de Carne Bovina, os custos aumentam, assim como, o preço ao consumidor desta proteína também é maior. A empresa mais estável em seus custos é a Minerva, onde os mesmos oscilam até 4\% (88\% em 2012 e 92\% em 2014), seguida da JBS com 6\% (77\% em 2019 e 83\% em 2012) e, por último, com maior variação (20\%) a Marfrig, que em 2012 apresentou seu menor custo $(66 \%)$ e em 2015, o maior (86\%).

Irani, Klabin e Suzano são do segmento Madeira e celulose; a Irani de menor porte com faturamento máximo no ano de 2019 de 1,5 milhões, custo de Insumos de $62 \%$ em 2010 e 51\% no ano de 2019, ressaltando que os custos de Insumos seguem tendência de 
queda ao logo do período analisado. Os faturamentos da Klabin e da Suzano são próximos de uma dezena de milhões até o ano de 2018. Em 2019, a receita da Suzano é superior a 31 milhões (94\% a mais que o ano anterior), pontualmente provocado pela aquisição da empresa Fimbria no ano de 2018. Quanto a proporção de Insumos destas duas empresas, para o ano de 2019, o percentual é aproximado (45\% - Klabin e 50\% - Suzano). Interessante observar que a Suzano sempre manteve custo de Insumos superior (média de $49 \%$ ), enquanto a Klabin, uma média de $40 \%$.

O segmento Têxtilé representado por Cedro, Dohler, Guararapes, Karsten e Santanense e a maior delas é a Guararapescom faturamento três vezes maior ao somatório das demais. Em termos de faturamento, Dohler e Santanense se mantêm estáveis, com discreto crescimento, enquanto Cedro e Karsten diminuem o faturamento ao longo dos anos. Com relação aos Insumos, Cedro e Santanense são as que possuem maior porcentagem média (61\%), com menor média de Insumos é a Karsten (41\%).

Os demais segmentos que compuseram a amostra são empresas com particularidades. A Heringer (Adubos e defensivos) apresentou receita atual 80\% menor que 2010, com percentual de Insumos crescente, superando as receitas em 2019. Do segmento Máquin, equip e ferram, a Metisa relatou queda de $10 \%$ do faturamento e, quanto aos Insumos, tendência de elevação no decorrer dos anos e por fim, a M Dias Branco, do segmento de Óleos, farinhas e conservas, mantêm crescimento no faturamento e no percentual de Insumos de $60 \%$ nos últimos anos.

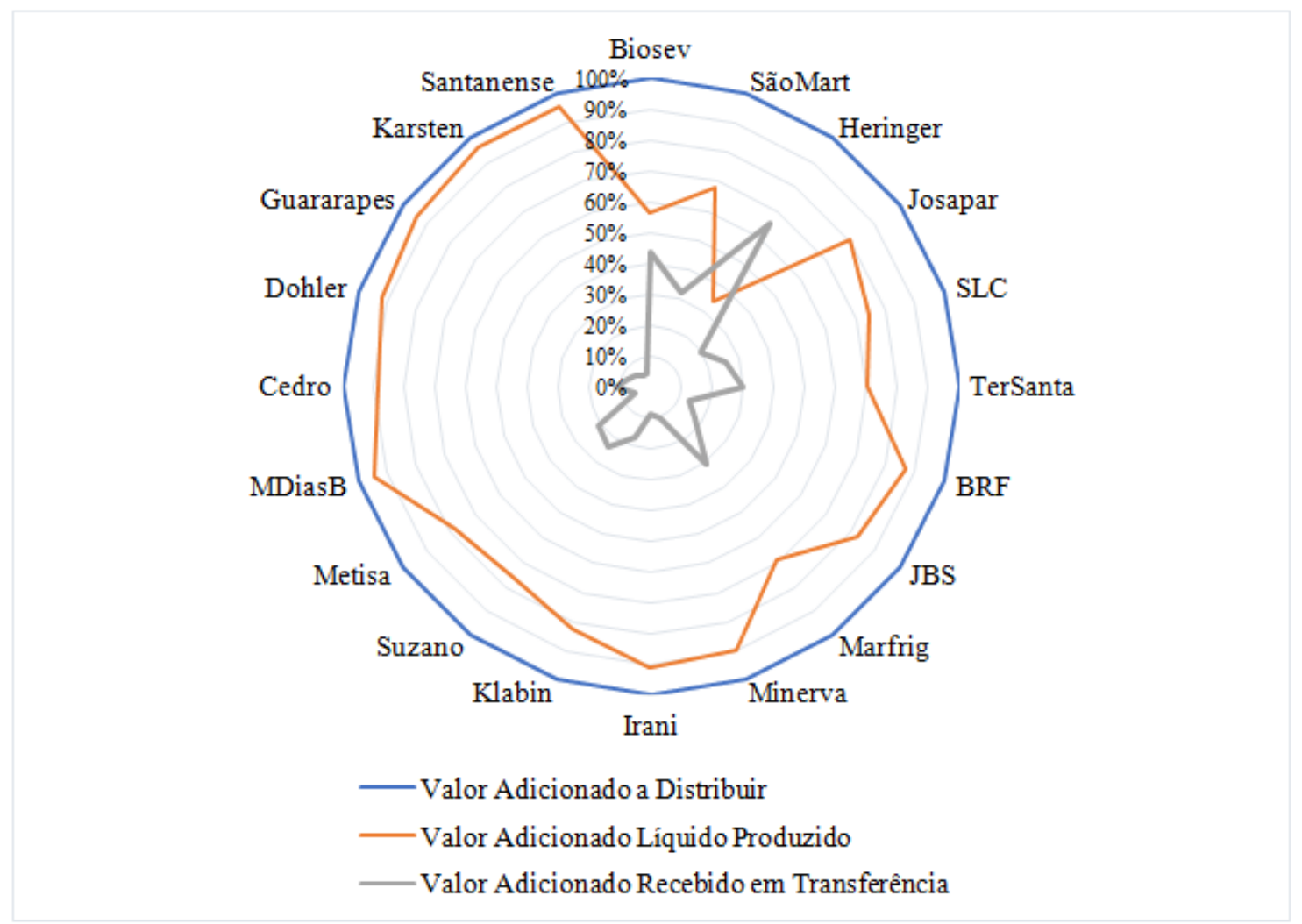

Figura 2. Valor Adicionado a Distribuir e proporções do Líquido Produzido e do Recebido em Transferência. 


\section{Composição do Valor Adicionado a distribuir}

As empresas deste estudo produzem a própria riqueza, porém, há discrepâncias apresentadas pelaBiosev e Heringer, em que o valor recebido em transferência é de $44 \%$ e $66 \%$, respectivamente, como apresenta a Figura 2.

A geração de riqueza própria se destaca no segmento Têxtil, em média $92 \%$ e o que produz menor riqueza própria é o setor de Álcool e açúcar (62\%). Os segmentos Madeira e celulose e proteína animal (Aves e suínos e Carne bovina) possuem criação de riqueza própria equivalente (82\%) e por fim, Algodão e grãos produziu em média $72 \%$ da riqueza distribuída.

\section{Distribuição do Valor Adicionado}

A distribuição de até $120 \%$, ou seja, além do Valor Adicionado a Distribuir, bem como, porcentagem negativa $(-80 \%)$ se destacam na avaliação deste quesito e são apresentadas pela linha pontilhada que se refere a Remuneração de Capitais de Terceiros, das empresas TerSanta (117\%), Minerva (99\%), Biosev (93\%), Heringer (82\%), Suzano (70\%) e Marfrig (62\%) (Figura 3). Para estas empresas, mais da metade do Valor Adicionado a Distribuir remunera capitais de Terceiros, especificamente o item "Juros".

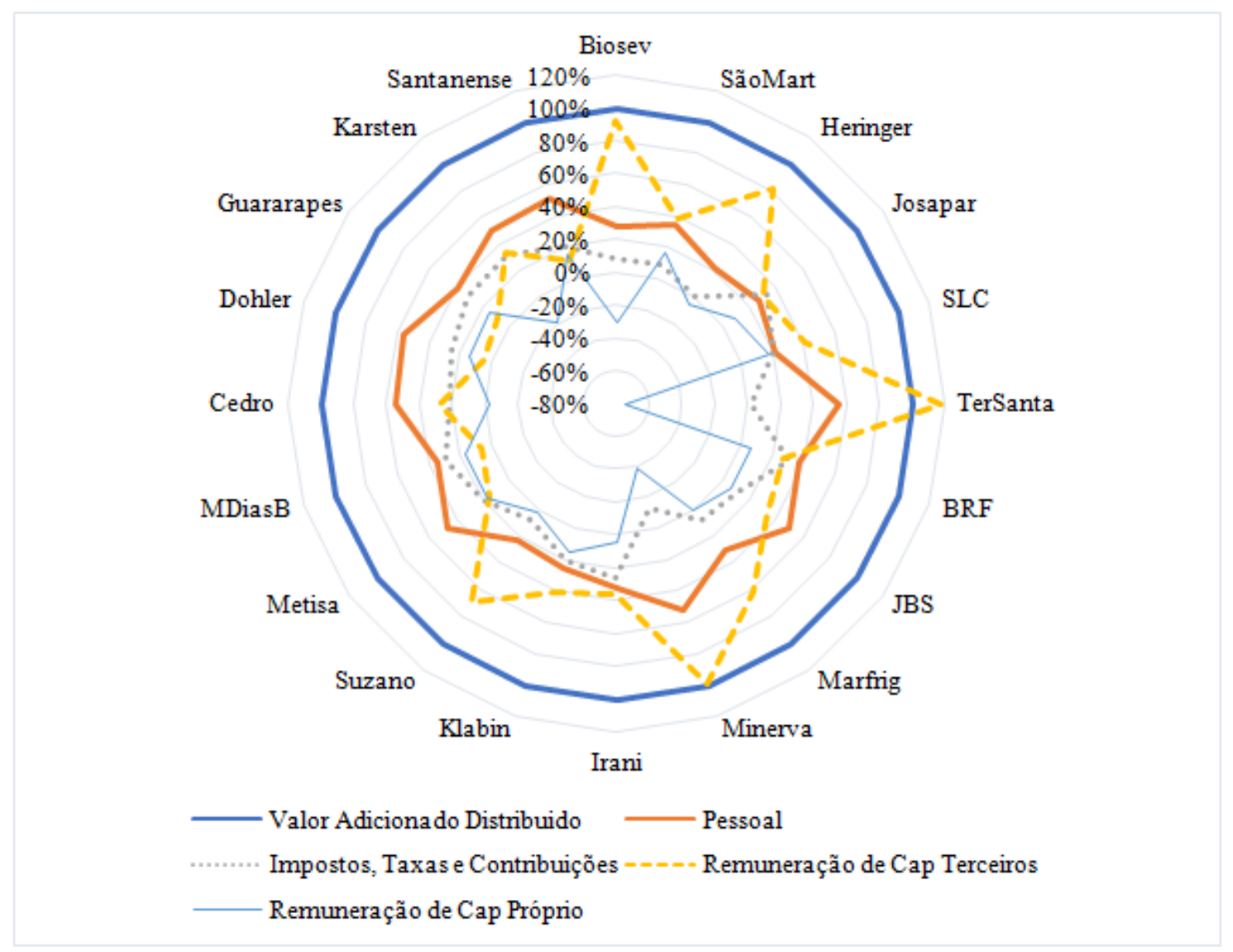

Figura 3. Distribuição do Valor Adicionado das empresas do agronegócio brasileiro de capital aberto.

Destaca-se que para esse fato, o valor remunerado a maior para Terceiros reflete valor negativo na Remuneração de Capitais Próprios, o que não significa que as empresas estejam operando ao longo dos anos analisados com sucessivos prejuízos. A empresa que 
menos remunera seu capital é a TerSanta, do segmento Algodão e grão, apresentando recuperação na sequência: $-476 \%$ no ano de 2013 e, no ano de 2019 com porcentagem, ainda negativa de $-56 \%$. A empresa que mais remunera seu capital é a SLC (18\%), seguida de SãoMart, Metisa e MDiasB, em 17\%.

A Distribuição do Valor Adicionado ao grupo Pessoal compreende a remuneração direta aos seus colaboradores internos e respectivos benefícios, a média geral do período é de 38\%, sendo a máxima de 56\% (Dohler) e a mínima de 21\% (SLC).

A maioria das empresas demonstra o valor composto por: remuneração direta, benefícios e FGTS, porém, algumas delas separam os valores distribuídos para a Administração Direta: SãoMart e Josapar, ao longo de todos os anos; MDiasB até o ano de 2015; Cedro até o ano de 2017; e, Guararapes a partir de 2017.0 segmento que mais pagou impostos foi o Têxtil (26\%), seguido de Madeira e celulose e Algodão e grãos (18\%) e, por último, Açúcar e álcool, Aves e suínos e Carne bovina (9\%), sendo a maior fatia à esfera federal.

Tabela 5. Média, Máxima e Mínima dos valores relativos e absolutos das empresas do agronegócio brasileiro de capital aberto (em milhares de Reais).

\begin{tabular}{|c|c|c|c|c|c|c|}
\hline \multirow{2}{*}{ Item da DVA } & \multicolumn{3}{|c|}{ Valores absolutos } & \multicolumn{3}{|c|}{ Valores relativos } \\
\hline & Média & Máximo & Mínimo & Média & Máximo & Mínimo \\
\hline \multirow{2}{*}{ Receitas } & \multirow{2}{*}{154.072 .475} & 1.608 .861 .493 & 3.681 .776 & \multirow{2}{*}{$100 \%$} & \multirow{2}{*}{$100 \%$} & \multirow{2}{*}{$100 \%$} \\
\hline & & JBS & Metisa & & & \\
\hline \multirow{2}{*}{$\begin{array}{l}\text { Insumos } \\
\text { Adquiridos de } \\
\text { Terceiros }\end{array}$} & \multirow{2}{*}{$-113.057 .153$} & -1.274 .204 .167 & -2.187 .304 & \multirow{2}{*}{$66 \%$} & $94 \%$ & $46 \%$ \\
\hline & & JBS & Karsten & & Heringer & SãoMart \\
\hline \multirow{2}{*}{$\begin{array}{l}\text { Valor Adicionado } \\
\text { Bruto }\end{array}$} & \multirow{2}{*}{41.015 .322} & 334.657 .326 & 1.188 .780 & \multirow{2}{*}{$34 \%$} & $54 \%$ & $6 \%$ \\
\hline & & JBS & Metisa & & SãoMart & Heringer \\
\hline \multirow{2}{*}{ Retenções } & \multirow{2}{*}{$-6.502 .065$} & -39.258 .973 & -85.053 & \multirow{2}{*}{$6 \%$} & $21 \%$ & $1 \%$ \\
\hline & & JBS & Karsten & & Biosev & Minerva \\
\hline \multirow{2}{*}{$\begin{array}{l}\text { Valor Adicionado } \\
\text { Líquido } \\
\text { Produzido }\end{array}$} & \multirow{2}{*}{34.513 .257} & 295.398 .353 & 1.089 .525 & \multirow{2}{*}{$28 \%$} & $47 \%$ & $5 \%$ \\
\hline & & JBS & Metisa & & Karsten & Heringer \\
\hline \multirow{2}{*}{$\begin{array}{l}\text { Valor Adicionado } \\
\text { Recebido em } \\
\text { Transferência }\end{array}$} & \multirow{2}{*}{8.204 .556} & 61.941 .416 & 79.791 & \multirow{2}{*}{$20 \%$} & $66 \%$ & $5 \%$ \\
\hline & & JBS & Santanense & & Heringer & Karsten e Santanense \\
\hline \multirow{2}{*}{$\begin{array}{l}\text { Valor Adicionado } \\
\text { a Distribuir }\end{array}$} & \multirow{2}{*}{42.717 .813} & 357.339 .770 & 1.386 .023 & \multirow{2}{*}{$100 \%$} & \multirow{2}{*}{$100 \%$} & \multirow{2}{*}{$100 \%$} \\
\hline & & JBS & Metisa & & & \\
\hline \multirow{2}{*}{ Pessoal } & \multirow{2}{*}{16.975 .971} & 178.064 .644 & 667.605 & \multirow{2}{*}{$39 \%$} & $56 \%$ & $21 \%$ \\
\hline & & JBS & Metisa & & Dohler & SLC \\
\hline Impostos, Taxas & 6787688 & 46.874 .474 & -1.155 .104 & $17 \%$ & $34 \%$ & $-13 \%$ \\
\hline e Contribuições & $0 . / 81.688$ & BRF & Minerva & $1 / \%$ & BRF & Minerva \\
\hline Federais & 3729913 & 25.354 .728 & -1.805 .605 & $11 \%$ & $21 \%$ & $-20 \%$ \\
\hline reuer dis & 0.129 .910 & $\mathrm{BRF}$ & Minerva & $11 \%$ & Karsten e Santanense & Minerva \\
\hline Fstaduais & 2955292 & 21.082 .014 & -408.891 & $6 \%$ & $21 \%$ & $-4 \%$ \\
\hline Estautuals & 2.953 .292 & BRF & Heringer & $0 \%$ & Josapar & Heringer \\
\hline Municinaic & 102483 & 797.511 & 857 & 0 & $2 \%$ & $0,0321 \%$ \\
\hline Miunicipais & 102.483 & Guararapes & Metisa & $0,3590 \%$ & Guararapes & SLC \\
\hline Remuneração de & 16770858 & 118.255 .003 & 122.136 & $44 \%$ & $117 \%$ & $5 \%$ \\
\hline Terceiros & $10.7 / 0.858$ & JBS & Dohler & $44 \%$ & TerSta & Dohler \\
\hline Remuneração de & 1972402 & 20.023 .361 & -7.708 .965 & 1 & $18 \%$ & $-75 \%$ \\
\hline Capitais Próprios & $1.9 / 3.403$ & JBS & Biosev & $-1 \%$ & SLC & TerSta \\
\hline
\end{tabular}




\section{Destaques da geração e distribuição da riqueza}

0 estudo compreende empresas de segmentos e localização diferentes, tendo em comum o fato de pertencerem ao agronegócio, ou seja, a atividade principal do empreendimento depende e gera riqueza a partir da produção agrícolaem que o início do processo está no uso de recursos naturais. Um resumo em valores absolutos e relativos da média, máximo e mínimo de cada elemento e respectiva empresa está apresentado na Tabela 5.

Para valores absolutos, a JBS apresenta valor máximo para a maioria dos itens expostos, o que corrobora a classificação das 400 Melhores e Maiores do Agro de 2019, em quarto lugar no ranking, competindo em tamanho com as internacionais Cargil Agrícola, ADM e Bunge. Com relação ao item Impostos, Taxas e Contribuições a BRF, quinto lugar do ranking, apresenta valor máximo de recolhimento nas esferas federal e estadual e, na esfera municipal, a Guararapes se destaca.

Os dados individuais de cada uma das empresas são discrepantes quanto comparados Impostos, Taxas e Contribuições e Receita. Enquanto a BRF possui impostos equivalentes a 10,87\%, a proporção para a JBS é de $2,55 \%$ e com relação a esfera municipal, a empresa em destaque é a Guararapes que, embora seja um valor pouco significativo em relação aos números discutidos, em termos percentuais, a desigualdade também se manifesta em: Guararapes 0,98946\%, BRF 0,10159, e JBS 0,01521\%.

Com relação aos valores mínimos, a Metisa se destaca na maioria dos itens, por ser a menor empresa do grupo analisado e, quanto a valores mínimos negativos, o destaque é para a rubrica Impostos, Taxas e Contribuições, que representam incentivos fiscais (TerSanta e Minerva (federal); e, Santanense (estadual)). Importante destacar que das empresas analisadas, além das citadas, há outras com ocorrência de valores negativos,porém, no somatório dos anos o valor é positivo.

Quanto aos valores relativos(\%) os Insumos empresa Heringer tem valor máximo e, no tocante ao mínimo, a SãoMart possui custos $27 \%$ inferior a Biosev do mesmo segmento. A Karsten se destaca com maior porcentagem no Valor Adicionado Líquido Produzido e a possui o menor, recebendo em transferência66\% do valor adicionado distribuído (juros).

A média para este grupo não representao conjunto de forma homogênea, pois valores máximos e mínimos estão afastados. Salienta-se a média da Remuneração de Capital de Terceiros de 44\% com destaque a TerSanta que remunera Capital de Terceiros em valor superior ao próprio Valor Adicionado a Distribuir.

\section{Discussão}

As empresas do mesmo segmento não possuem igual consumo de insumos, como por exemplo a SLC que, comparada à duas empresas semelhantes, opera com valor de insumos $8 \%$ menor. Para os valores retidos, o comportamento é equivalente para a maioria das empresas, se destacando Biosev (21,22\%) e SãoMart (20,03\%), ambas do segmento Açúcar e álcool. A maior produção e distribuição de riqueza é do segmento Têxtil (média de 92\%). As empresas Biosev e Heringer recebem em transferência 44\% e $66 \%$, respectivamente do Valor Adicionado distribuído.

Percentualmente quem destina maior parte do Valor Adicionado ao item pessoal é a Dohler (56\%) e, a menor destinação, é da SLC (21\%). Os valores distribuídos para o item Pessoal é o mais estável e a atenção volta-se para a questão da remuneração do operacional e da administração direta, onde somente algumas empresas abrem estes valores (SãoMart e Josapar, ao longo de todos os anos; MDiasB até 2015; Cedro até 2017; e, Guararapes a partir de 2017). Este é um aspecto detectado por Almeida e Silva (2014), que encontraram deficiência na comparabilidade das DVAs de diferentes empresas, o que compromete a utilidade da informação contábil. Os mesmos autores salientam ainda que a 
estrutura da norma contábil proposta pelo Comitê de Pronunciamentos Contábeis (CPC) aumenta a liberdade de tratamento dos dados aqueles que elaboram a demonstração.

A fatia destinada ao Estado (média de 39\%) tem como maior distribuidor o segmento Têxtil (26\%) e menor, Açúcar e álcool, Aves e suínos e Carne bovina (9\%), sendo a esfera federal a que mais recebe. A proporção entre Receita e Tributação não são equivalentes, com destaque às duas maiores empresas em que os impostos equivalem a 10,87\% para BRF e de 2,55\% para JBS.Estes resultados divergem do estudo de Tinoco et. al. (2011), quando nos anos de 2005 e 2007 o setor Têxtil possuía carga tributária maior em 4\%. A maior discrepância está no setor Atacado de Alimentos, em que faziam parte as empresas Sadia e Perdição, com tributação de 34\% e, Papel e Celulose (Suzano e Klabin) de 28\%. Silva et al. (2021), analisam o biênio 2017 e 2018 e apontam o setor Algodão e grãos com maior distribuição à Impostos, o que também diverge do presente estudo.

Na distribuição da riqueza a Remuneração de Capitas de Terceiros é a que mais se destaca (média de 44\%), sendo que para algumas empresas, mais da metade do Valor Adicionado a Distribuir é destinado à esta rubrica (TerSanta 117\%; Minerva 99\%; Biosev 93\%; Heringer 82\%; Suzano 70\%; e Marfrig 62\%). Silva et al. (2020) e Costa e Valentim (2021) estudaram a distribuição de riqueza de empresas seguradoras e bancos apontando a Remuneração de Capitais de Terceiros a menor parcela de distribuição, enquanto a maior é para Remuneração de Capital Próprio. Esta comparação evidencia a disparidade de destinação dos recursos nos setores econômicos brasileiros, pois nas empresas do agronegócio, o capital próprio é o que menos recebe.

Dos aspectos teóricos apontados pela presente pesquisa, é visível a capacidade de comunicação da DVA em relatar como uma empresa cria valor (Luca, 1998; Santos, 2007; Iudícibus et al., 2010). Porém, há uma perspectiva informacional quanto a responsabilidade social da empresa, demonstrando a remuneração dos fatores de produção (Cunha, 2002; Santos, 2007) que é reportado pela empresa de forma muito ampla, não indicando como isso ocorre na localização física destas. Um exemplo dessa problemática é apontado por Melo et al. (2017) que buscaram associar a distribuição da riqueza nas cinco regiões do Brasil, apontando para a dificuldade de identificação e inequidade entre as regiões.

Degenhard et al. (2014) e Londero et al. (2019) analisam empresas ligadas ao agronegócio, apontando para a falta de relação das DVAs do agronegócio com o PIB e uma distribuição de recursos onde a ordem de distribuição é: Pessoal, Governo, Capitais de Terceiros e Próprios, corroborando em parte aos resultados, em que $49 \%$ são destinados para o grupo Pessoal, seguido de 25\% para a Remuneração de Capitais de Terceiros, $20 \%$ para Impostos, taxas e contribuições (20\%), e por último, 6\% à Remuneração de Capitais Próprios. A Remuneração do Capital Próprio é singular entre as empresas analisadas e irregular ao longo do período analisado, observando que a empresa que mais remunera é a SLC.

Outros segmentos da economia também se demonstram com distribuições diferentes ao deste estudo, como detectado por Cardoso et al. (2015), em que maior distribuição foi para Impostos, Taxas e Contribuições (Telecomunicações, Energia e a Indústria Digital). As informações agregadas no item pessoal, em que a remuneração à Administração Direta não está evidenciada, corrobora com Maciel, Dantas e Botelho (2018), que observam que formas não padronizadas de relato fragilizam a análise de determinados itens.

\section{Considerações finais}

0 presente estudo explorou as informações da criação e da geração do Valor Adicionado das empresas do agronegócio que possuem ações negociadas na B3 e corroborou estudos anteriores que apontam necessidade de pesquisa nas áreas de 
contabilidade e de sustentabilidade no agronegócio com base em mecanismos e informações contábeis (Zanella e Lago, 2017; Callado et al., 2017).

Os resultados demonstraram que empresas do mesmo segmento não possuem igual consumo de insumos, como por exemplo a SLC que, comparada à duas empresas semelhantes,opera com valores $8 \%$ menor. Para valores retidos, o comportamento é equivalente para a maioria das empresas, se destacando Biosev $(21,22 \%)$ e SãoMart $(20,03 \%)$, ambas do segmento Açúcar e álcool. A maior produção e distribuição de riqueza é do segmento Têxtil (média de 92\%) e Biosev e Heringer recebem em transferência 44\% e $66 \%$, respectivamente.

Na distribuição da riqueza a Remuneração de Capitas de Terceiros é a que mais se destaca e, para algumas empresas, mais da metade do Valor Adicionado a Distribuído é destinado à esta rubrica. Percentualmente quem destina maior parte do Valor Adicionado ao item pessoal é a Dohler (56\%) e, a menor destinação, é da SLC (21\%). Os valores distribuídos para o item Pessoal é o mais estável e a atenção volta-se para a questão da remuneração do operacional e da administração direta, onde somente algumas empresas abrem estes valores (SãoMart e Josapar, ao longo de todos os anos; MDiasB até 2015; Cedro até 2017, e Guararapes a partir de 2017). Este é um aspecto apresentado por Almeida e Silva (2014), que encontraram deficiência na comparabilidade das DVAs de diferentes empresas, o que compromete a utilidade da informação contábil. Os mesmos autores salientam ainda que a estrutura da norma contábil proposta pelo Comitê de Pronunciamentos Contábeis (CPC) aumenta a liberdade de tratamento dos dados aqueles que elaboram a demonstração.

A fatia destinada para o Estado do Valor Adicionado aponta como maior distribuidor o segmento Têxtil (26\%) e menor, Açúcar e álcool, Aves e suínos e Carne bovina (9\%) e, a esfera federal a que mais recebe. Destaca-se que a maior Receita não equivale a maior Tributação, com destaque às duas maiores empresas em que os impostos equivalentes às receitas são de $10,87 \%$ para BRF e de $2,55 \%$ para JBS. Do montante do Valor Adicionado a Distribuir, 49\% são destinados para o grupo Pessoal, seguido de $25 \%$ para a Remuneração de Capitais de Terceiros, ou seja, para pagamento de juros. Em terceiro lugar os recursos são destinados para Impostos, taxas e contribuições (20\%), e por último, 6\% à Remuneração de Capitais Próprios. A Remuneração do Capital Próprio é singular entre as empresas analisadas e irregular ao longo do período analisado, observando que a empresa que mais remunera é a SLC.

0 presente estudo limitou-se a uma análise vertical de números absolutos e relativos, assim como os dados discutidos abrangem informações presentes da DVA. Quanto ao propósito de novos estudos e/ou sequência deste, indica-se primeiramente estudos mais focados nos itens específicos da DVA, como a distribuição para Impostos, Taxas e Contribuições em que se descreva possíveis motivos para uma tributação desigual como a apontada nesta pesquisa. Também, sugere-se analisar a estrutura de capital das empresas e a relação da distribuição à Remuneração de Capitais de Terceiros, em que podem surgir evidências de má gestão dos recursos disponíveis, assim como dos fluxos de caixa. Ainda, foi observado que mesmo empresas de segmentos semelhantes possuem Insumos que se diferenciam proporcionalmente, neste sentido, a localização da empresa ou o mercado a quem se destina a produção, se nacional ou internacional pode explicar ou não essa questão.

\section{Conflito de interesses}

Os autores declaram não haver conflito de interesses. 


\section{Referências}

Almeida, R. L.; Silva, A. H. C. Demonstração do Valor Adicionado (DVA): uma análise de sua comparabilidade após tornar-se obrigatória no Brasil. Revista de Contabilidade do Mestrado em Ciências Contábeis da UERJ, v. 19, n. 1, p. 95-110, 2014.

B3 - Bolsa Brasil Balcão. Empresas listadas. Disponível em: <http://www.b3.com.br/ pt_br/produtos-e-servicos/negociacao/renda-variavel/empresas-listadas.htm>. Acesso em: 08 out. 2020.

BRASILABRO. 0 agronegócio responde por 21,1\% do PIB brasileiro. 2020. Disponível em: $<$ https://www.brasilagro.com.br/conteudo/o-agronegocio-responde-por-211-do-pibbrasileiro.html>. Acesso em: 10 out. 2020.

Brundtland, G. H. (Org.). Nosso futuro comum. Rio de Janeiro: FGV, 1987.

Callado, A. L. C.; Silva, S. C.; Silva, A. R. Sustentabilidade empresarial no contexto do agronegócio: um estudo bibliométrico. Gestão e Desenvolvimento em Revista, v. 3, n. 1, p. 4-19, 2017.

Camargos, D.; Campos, A. Fogo no pantanal mato-grossense começou em fazendas de pecuaristas que fornecem para gigantes do agronegócio. 2020. Disponível em: <https://reporterbrasil.org.br/2020/09/fogo-no-pantanal-mato-grossense-comecou-emfazendas-de-pecuaristas-que-fornecem-para-gigantes-do-agronegocio/>. Acesso em: 10 out. 2020.

Cardoso, T. L.; Ferreira, L. F.; Malagotti, L.; Lohn, J. Distribuição de riqueza aos agentes econômicos: um olhar sobre a DVA. Anais do XII Congresso USP de Iniciação Científica em Contabilidade "Contabilidade e Controladoria do Século XXI", São Paulo, 2015.

CEPEA - Centro de Estudos Avançados em Economia Aplicada. PIB do Agronegócio Brasileiro. 2020. Disponível em: <https://www.cepea.esalq.usp.br/br/pib-doagronegocio-brasileiro.aspx>. Acesso em 10 out. 2020.

CIMI - Conselho Indígena Missionário. 0 agro é fogo: queimadas são responsabilidade do agronegócio. 2020. Disponível em: <https://cimi.org.br/2020/10/agro-e-fogo-queimadascriminosas/>. Acesso em 30 out. 2020.

CNA - Confederação Nacional de Agricultura. Panorama do agro. 2020. Disponível em: <https://www.cnabrasil.org.br/cna/panorama-do-agro>. Acesso em 10 out. 2020.

Costa, L. V. G.; Valentim, I. C. D. Demonstração do Valor Adicionado: uma análise dos bancos listados na B3. 2021. Disponível em: <https://www.iesp.edu.br/sistema/uploads/ arquivos/publicacoes/demonstracao-do-valor-adicionado-uma-analise-dos-bancos-

listados-na-b3-autor-a-costa-ladyjane-vito-goncalves-da-.pdf>. Acesso em: 21 abr. 2021.

CPC - Comitê de Pronunciamentos Contábeis. Pronunciamento Técnico CPC 09 Demonstração do Valor Adicionado. Disponível em: <http://www.cpc.org.br/ $\mathrm{CPC} /$ Documentos-Emitidos/Pronunciamentos/Pronunciamento?Id=40>. Acesso em 08 out. 2020.

Cunha, J. V. A.; Ribeiro, M. S.; Santos, A. A demonstração do valor adicionado como instrumento de mensuração da distribuição da riqueza. Revista Contabilidade e Finanças, n. 37 p. 7-23, 2005.

Degenhart, L.; Vogt, M.; Hein, N. Análise da relação do Produto Interno Bruto dos municípios do Estado de Santa Catarina com as demonstrações do valor adicionado. Revista Contemporânea de Contabilidade, v. 11, n. 24, p. 125-142, 2014.

Diniz, N. Análise das demonstrações financeiras. Rio de Janeiro: Seses, 2015. 
EMBRAPA - Empresa Brasileira de Pesquisa Agropecuária. Webinar aponta mitos e verdades do agro. 2020. Disponível em: <https://www.embrapa.br/en/busca-denoticias/-/noticia/55525834/webinar-aponta-mitos-e-verdades-do-agro>. Acesso em: 10 out. 2020.

Exame. 400 Maiores Agronegócio 2019. São Paulo: Abril, 2019. Disponível em: $<$ https://exame.com/revista-exame/400-maiores-do-agronegocio-3/>. Acesso em: 01 out. 2020.

IBGE - Instituto Brasileiro de Geografia e Estatística. Inflação. Disponível em: <https://www.ibge.gov.br/explica/inflacao.php>. Acesso em: 12 nov. 2020.

Iudícibus, S.; Martins, E.; Gelbcke, E. R.; Santos, A. Manual de contabilidade societária: aplicável a todas as sociedades de acordo com as normas internacionais e do CPC. 3. ed. São Paulo: Atlas, 2018.

Londero, P. R.; Stanzani, L. M. L.; Santos, A. Uma análise da contribuição econômica e social das cooperativas agropecuárias brasileiras pela Demonstração do Valor Adicionado. Revista de Educação e Pesquisa em Contabilidade, v. 13, n. 3, p. 291-309, 2019.

Luca, M. M. M. Demonstração do valor adicionado: do cálculo da riqueza criada pela empresa ao valor do PIB. São Paulo: Atlas, 1998.

Machado, M. A. V.; Macedo, M. A. S.; Machado, M. R. Análise da relevância do conteúdo informacional da DVA no mercado brasileiro de capitais. Revista Contabilidade \& Finanças, v. 26, n. 67, p. 57-69, 2015

Maciel, J. V. S. P.; Dantas, J. A.; Botelho, D. R. Evidenciação do ajuste a valor justo na DVA por empresas que exploram ativos biológicos. Custos e @gronegócio on line, v. 14, n. 4, p. 377-400, 2018.

Marion, J. C. Análise das demonstrações contábeis. 8. ed. São Paulo: Atlas, 2019.

Matarazzo, D. C. Análise financeira de balanços: uma abordagem gerencial. 7. ed. São Paulo: Atlas, 2010.

Melo, F. L.; Rover, S.; Ferreira, D. D. M.; Ferreira, L. F. Demonstração do Valor Adicionado (DVA): um estudo sobre a destinação da riqueza nas regiões brasileiras. Revista Metropolitana de Sustentabilidade, v. 7, n. 2, p. 68-92. 2017.

Perez Junior, J. H.; Begalli, G. A. Elaboração e análise das demonstrações financeiras. 5. ed. São Paulo: Atlas, 2015.

Santos, A. Demonstração do valor adicionado: como analisar e elaborar a DVA. 2. ed. São Paulo: Atlas, 2007.

Silva, M. J. R. V.; Oliveira, E.; Gonzales, A. G. Demonstração do Valor Adicionado (DVA): o retorno econômico das empresas do agronegócio no biênio 2017 e 2018 listadas na B3 em relação à distribuição da riqueza aos agentes econômicos. Revista Facet Zona Sul, v. 7, n. 3, p. 34-53, 2021.

Silva, R. C.; Freschi, E. A.; Gimenez, J. M. N.; Henequi, L.; Souza, H. A. Construtoras Cyrela e MRV: uma análise de indicadores da Demonstração do Valor Adicionado no período de 2008 a 2018. Anais do XVII Congresso USP de Iniciação Científica em Contabilidade "a Contabilidade como mecanismo de Governança", São Paulo, 2020.

Tinoco, J. E. P.; Kraemer, M. E. P. Contabilidade e gestão ambiental. 3. ed. São Paulo: Atlas, 2011. 
Tinoco, J. E. P.; Moraes, P. B.; Peleias, I. R.; Claro, J. A. C. S.; João, B. N. Estudo sobre a carga tributária de empresas brasileiras através da demonstração do valor adicionado (DVA): período de 2005 A 2007. Revista Ciências Administrativas, v. 17, n. 1, p. 84-111, 2011.

Zanella, T. P.; Lago, S. M. S. A produção científica brasileira sobre a sustentabilidade no agronegócio: um recorte temporal entre 2005 e 2015. Organizações Rurais e Agroindustriais, v. 18, n. 4, p. 356-370, 2017. https://doi.org/10.21714/223868902016v18n4p356 